\title{
High-Resolution Hybrid Imaging Could Improve Cordotomy Lesions and Outcomes
}

W e have read with great interest the paper by Vedantam et $\mathrm{al}^{1}$ concerning the postoperative evaluation of cordotomy with MR imaging. We agree that this is a very important step to assess treatment efficacy. Indeed, lesion localization is of prime importance; this underlines another potential of multimodal hybrid rooms. We believe that, given the proper tools, perioperative visualization of the electrode could be performed under MR guidance. Although the electrode itself may generate artifacts, it should be possible to perform improved navigation because of the superior differentiation between gray matter and the spinothalamic tracts on MR imaging compared with CT. In addition, diffusion tensor imaging performed before implantation, and even during the procedure, could also help to improve the precision of electrode placement as well as to allow better visualization and delineation of the tracts. Thus, the use of a combined MR and operating table should allow this to be performed safely. At the moment, these techniques can be applied only at the level of the cervical spine. On the other hand, by using combined MR operative techniques as well as eventually moving to higher fields, it should be possible to improve lesion delineation. A higher field, in addition to a higher resolution, should allow improved acquisition of gradient-echo images, which have been shown to provide

http://dx.doi.org/10.3174/ajnr.A5269 the best gray-white matter differentiation. ${ }^{2,3}$ Finally, this should allow cordotomy, resulting in smaller and better-localized postprocedure lesions that would correspond to the $20 \%$ of cord area that is necessary for an acceptable clinical outcome. ${ }^{4}$

\section{REFERENCES}

1. Vedantam A, Hou P, Chi TL, et al. Postoperative MRI evaluation of a radiofrequency cordotomy lesion for intractable cancer pain. AJNR Am J Neuroradiol 2017;38:835-39 CrossRef Medline

2. Zhao W, Cohen-Adad J, Polimeni JR, et al. Nineteen-channel receive array and four-channel transmit array coil for cervical spinal cord imaging at 7T. Magn Reson Med 2014;72:291-300 CrossRef Medline

3. Massire A, Taso M, Besson P, et al. High-resolution multi-parametric quantitative magnetic resonance imaging of the human cervical spinal cord at 7T. Neuroimage 2016;143:58-69 CrossRef Medline

4. Lahuerta J, Bowsher D, Lipton S, et al. Percutaneous cervical cordotomy: a review of 181 operations on 146 patients with a study on the location of "pain fibers" in the C-2 spinal cord segment of 29 cases. J Neurosurg 1994;80:975-85 CrossRef Medline

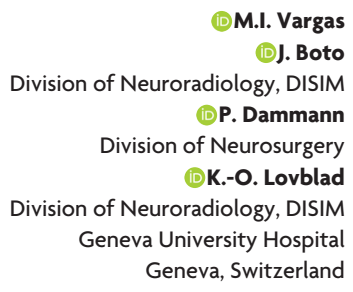

